\title{
A gestão da Extensão na UNIRIO no período 2004-2008: seguindo as trilhas do FORPROEX para avaliação
}

Extension Management at UNIRIO - period 2004-2008: under FORPROEX guidelines for evaluation

\section{Maria do Carmo Ferreira', Regina Guedes Moreira Guimarães ${ }^{2}$}

\section{Do assistencialismo à comunicação- participação: a transformação da extensão universitária no Brasil}

No Brasil, a extensão teve seu primeiro registro oficial no Estatuto da Universidade Brasileira, em 1931, aparecendo como curso, conferências e outras ações ${ }^{1}$. Em 1961, na Lei de Diretrizes e Bases da Educação Nacional ${ }^{2}$ a extensão aparece como modalidade de curso e assistência rural, destinada à clientela ligada à universidade. Nos anos 60, se destaca a sua expressão participativa, dialógica e problematizadora, defendida pelo Movimento Estudantil brasileiro, inspirado nas idéias e prática do educador Paulo Freire.

Finalmente, na década de 80 , consolidou-se um novo paradigma de Universidade em que a população deixa de ser percebida como simples receptora de conhecimentos e de práticas produzidas no interior do "castelo do saber" e a participação passa a ser considerada crucial, enquanto imperativo democrático. ${ }^{3}$

A concepção de extensão como participação e diálogo é então consagrada em documento produzido pelo Fórum de Pró-Reitores de Extensão das Universidades Públicas Brasileiras - FORPROEX, quando da sua criação em 1987², e a indissociabilidade ensino-pesquisa-extensão é institucionalizada na $6^{a}$ Carta Magna Brasileira. ${ }^{4}$

A partir da década de 90, intensifica-se a implementação de uma política de extensão universitária, destacada nos trabalhos de diversos autores e em documentos gerados pelo FORPROEX, em especial os da Coletânea Universitária. 3, 5, 6,7

Enfoca-se, então, que a dimensão social das universidades se refaz no trabalho da extensão universitária, quando constituída por meio de metodologias de ensino participativas em apoio

\section{Resumo}

Na segunda metade do século passado, a institucionalização da extensão universitária no Brasil foi especialmente defendida e referenciada na necessidade de superação do modelo assistencialista para o modelo participativo junto às comunidades parceiras, no dimensionamento da indissociabilidade entre ensino, pesquisa e extensão, tendo a flexibilização curricular como meio de implementação, no emprego de metodologias participativas e na avaliação contínua sobre todo o processo desenvolvido. O presente trabalho objetiva apresentar e discutir aspectos da Gestão da Extensão, período 2004- 2008, na Universidade Federal do Estado do Rio de Janeiro - UNIRIO, utilizando as diretrizes de avaliação definidas pelo Fórum de Pró-Reitores de Extensão das Universidades Públicas Brasileiras - FORPROEX. O estudo evidenciou: incremento da formalização e da organização da extensão na estrutura universitária; aprimoramento da interação extensão-ensino-pesquisa, apoiada pela flexibilização curricular; fortalecimento do diálogo interno na instituição; ampliação do programa de bolsas acadêmicas e implementação de critérios de regulação, registro e avaliação das ações de extensão. Novos desafios se desvelaram: implantação definitiva de um sistema de informação fundamental para a avaliação; a ampliação de fomento; expansão de ações a comunidades e segmentos sociais e expansão de parcerias institucionais; organização da prestação de serviços, vinculada a Programa de Extensão.

Palavras-chaves: Formalização e organização da extensão; Flexibilização Curricular; FORPROEX

Área Temática: Educação

Linha da Extensão: Gestão institucional

1 Professor Adjunto IV; Doutora em Parasitologia, UNIVERSIDADE FEDERAL RURAL DO RIO DE JANEIRO - UFRRJ, Diretora do Departamento de Extensão - DEX PROEX / UNIRIO na Gestão 2004-2008

E-mail: mcarmoferreira@unirio.br.

U-mIil: mcarmoterreira@unirio.br.

Rua Frei Caneca, 94. Centro Rio de Janeiro - CEP 20511.044

2 Professor Associado I: Doutora em Saúde Pública - ENSP / FIOCRUZ, Pró-Reitora de Extensão e Assuntos Comunitários - PROEX / UNIRIO na Gestão 2004-2008; E-mail: rgguima@hotmail.com.

E-mail: rgguima@hotmail.com. pêutica Complementa

Rua Mariz e Barros 775, Tijuca - Rio de Janeiro - CEP - 20270-901 
às políticas públicas. A formação cidadã nas universidades pretende, assim, priorizar a qualidade de vida, o desenvolvimento sustentável e a responsabilidade humana sobre os fenômenos da vida. Pensa-se que a educação atente para as categorias de aceitação do outro, cooperação, autonomia, diálogo, responsabilidade social, que se opõem ao preconceito, competição, poder, obediência, autoritarismo, arrogância, prepotência, cinismo e dissimulação, criticados na construção da identidade profissional. . $^{8,10}$

Com esse referencial, a institucionalização da extensão universitária no Brasil nas últimas quatro décadas tem sido defendida principalmente no seguinte panorama: a) na necessidade de superação do modelo assistencialista para o modelo participativo junto às comunidades parceiras; $b$ ) no dimensionamento da indissociabilidade entre ensino, pesquisa e extensão, tendo a flexibilização curricular como meio de implementação; c) no emprego de metodologias participativas; e d) na avaliação contínua sobre todo o processo desenvolvido.

Buscando contribuir com os debates na linha de gestão institucional, é especialmente nesse sentido que as autoras, após finalizarem o período de gestão 2004-2008, enquanto dirigentes da Extensão Universidade Federal do Estado do Rio de Janeiro - UNIRIO, se colocam diante do desafio de refletir sobre o processo aí desenvolvido, utilizando as diretrizes de avaliação definidas pelo Fórum de Pró-Reitores de Extensão das Universidades Públicas Brasileiras - FORPROEX.

\section{Os parâmetros metodológicos para a avaliação da extensão universitária}

As diretrizes para a avaliação da extensão universitária definidas em 2001 pelo FORPRO$\mathrm{EX}^{7}$ são ferramentas imprescindíveis à prática da extensão, na realização de suas atividades e na gestão. Esses parâmetros asseguram a promoção do distanciamento, necessários ao 'olhar' sobre o quê e como se faz.

Três níveis de abordagem com indicadores gerais se destacam e permitem aferir o alcance das metas. São eles: o compromisso institucional, os impactos sociais e a formalização de instrumentos de avaliação.
As seguintes dimensões constituem componentes imprescindíveis à avaliação: a política de gestão e infraestrutura; a relação universidade-sociedade; o plano acadêmico e a produção científica.

Essa metodologia permite criar um desenho dos avanços conquistados e indicar os novos desafios a superar no âmbito da extensão universitária, dando visibilidade ao trabalho desenvolvido e permitindo o acompanhamento de estudos nesse campo.

\section{Um olhar sobre a extensão na UNIRIO: visualizando os resultados}

Nas duas últimas décadas, é na Extensão que a UNIRIO tem desenvolvido sua vocação mais genuína, mobilizando a comunidade com ações integradoras e participativas desde $1993^{11}$.

A gestão desenvolvida no período de setembro de 2004 a setembro de 2008 fortaleceu-se com a aprovação da implementação da Pró-Reitoria de Extensão e Assuntos Comunitários - PROEX pelo Conselho Universitário, em outubro de 2004. Formada a equipe administrativa da PROEX, o trabalho se desenvolveu integrado a um grupo de professores e profissionais, constituindo uma rede.

Quanto à política nacional, a UNIRIO tem tido importante participação junto aos programas apoiados pelo Ministério da Educação / SESu, concorrendo com propostas ao PROEXT, desde 2003, recebendo apoio anualmente. ${ }^{12,13,14,15,16}$ Do mesmo modo, em 2007 e 2008, participaram exitosamente $^{17}$ da concorrência com ao Edital do PROEXT-Cultura / MINC.

Com base nas dimensões definidas para a avaliação da extensão universitária, uma síntese das ações desenvolvidas, na UNIRIO e no período estudado, é apresentada no Quadro.

A análise deu visibilidade à extensão na UNIRIO e destacou os indicadores gerais definidos pelo FORPROEX. O compromisso institucional reafirmou-se com: a) a formalização da extensão na estrutura universitária; b) a definição das políticas institucionais, em seus Planos específicos; c) a ampliação dos diálogos internos na PROEX, junto à Câmara de Extensão, aos responsáveis por ações de Extensão, aos Bolsistas de Extensão e aos colegiados de Curso de Graduação, no sentido de consolidar a conceituação de 


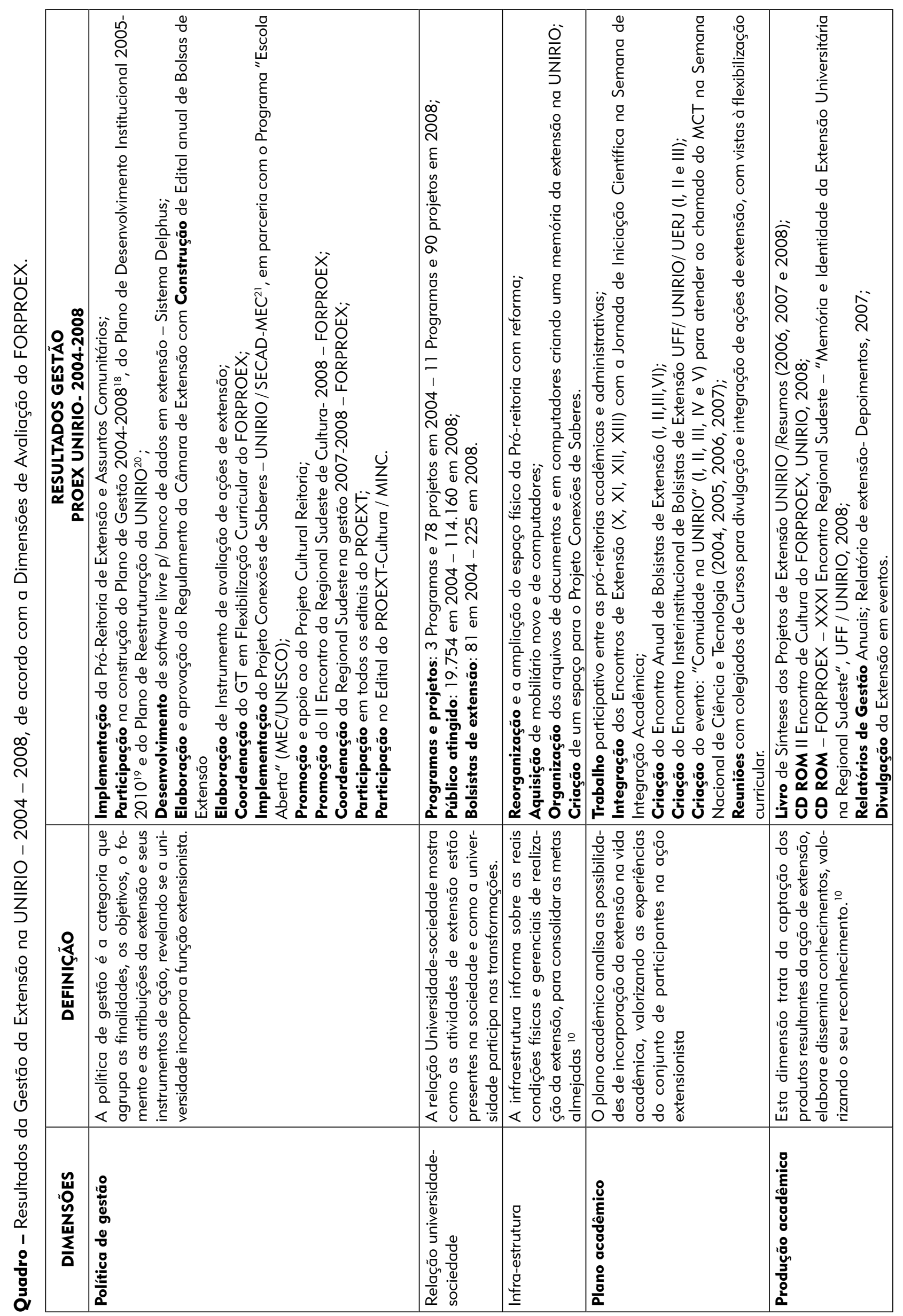


extensão e a tipologia das atividades de extensão; d) maior participação do orçamento da UNIRIO, com a criação do Programa de Bolsas Acadêmicas e maior apoio à infra-estrutura dos eventos; e) o fortalecimento do envolvimento dos docentes em atividades de extensão, ao promover a integração entre eles e entre as atividades; f) o envolvimento dos Departamentos em Programas e Projetos de Extensão como um dos critérios para a alocação de vagas docentes; g) a interação extensão-ensino-pesquisa, como o estabelecimento de critérios de registro e de avaliação no âmbito da flexibilização curricular e regulação para tal.

Quanto aos impactos sociais das atividades de extensão:

a) Foram contemplados e priorizados programas, projetos e eventos que envolvessem diversos segmentos sociais, acompanhando políticas locais e nacionais; b) Ampliaram-se as parcerias com órgãos públicos e privados e segmentos organizados; c) Foram criados produtos, publicações e organizados eventos, junto às comunidades envolvidas nas atividades de extensão, o que evidenciou a apropriação, utilização e reprodução do conhecimento pelos parceiros, transformando o espaço universitário em verdadeiro espaço público para as comunidades participantes da extensão; d) Ampliou-se o escopo dos efeitos da interação resultante das ações de extensão articuladas com o ensino e a pesquisa.

Quanto à formalização de instrumentos específicos que envolveram as instâncias acadêmicas na avaliação da Extensão Universitária, foram criados regulamentos, editais, instrumentos de avaliação e registro das ações, entre outros.

Os indicadores quantitativos revelaram o aumento do número de atividades de extensão, de seus produtos e publicações, bem como de profissionais, de estudantes e de comunidades envolvidas em atividades de extensão.

\section{Abrindo perspectivas: enfrentando os desafios}

As diretrizes para avaliação da extensão universitária possibilitaram a visualização do desenvolvimento da Extensão Universitária na UNIRIO no período de 2004 a 2008, denotando a feição de sua contribuição para a identidade institucional. Por outro lado, o estudo indicou os avanços necessários e as perspectivas para a Extensão Universitária na UNIRIO.

$\mathrm{Na}$ dimensão acadêmica, se confirmou a necessidade de realização mais abrangente da flexibilização curricular para as ações de extensão, quando então a universidade pode consistentemente assumir seu compromisso social. A ampliação do número de Programas e Projetos por meio de parcerias e fomentos associados incrementará o envolvimento de estudantes e professores em atividades de extensão, com regulação específica para inclusão de créditos em extensão nos cursos de graduação e pós-graduação.

Para tanto, a publicação plena das atividades no sistema de informação de extensão é fundamental para a divulgação e para a avaliação, com demonstração abrangente de dados quanti-qualitativos e a consequente possibilidade de definição de políticas de extensão a serem priorizadas em dado período. Com isto, se fortalece a organização das representações nas Áreas Temáticas de Extensão e a política institucional a elas concernente, o que viria a auxiliar também a criação de ações no âmbito da prestação de serviços, vinculada a Programas e Projetos de Extensão.

O enfrentamento das dificuldades desveladas é encorajado pelas perspectivas positivas que a extensão universitária incita, na medida em que sua prática imprescindivelmente convida ao convívio com a comunidade externa, em que se consolidam espaços de encontro e de criação.

Definem-se desse modo trajetórias expressivas para a concretização de uma prática acadêmica aberta à diversidade e às múltiplas formas de construção do conhecimento, reafirmando e expandindo a missão da universidade como instituição pública para a formação profissional de cidadãos compromissados.

\section{Referências}

1. NOGUEIRA, M.D.P. Políticas de Extensão Universitária Brasileira. Belo Horizonte: Ed UFMG, 2005. 135p.

2. BRASIL. Lei $\mathrm{n}^{\circ}$ 9.394, de 20 de dezembro de 1996. Estabelece as diretrizes e bases da educação nacional. Diário Oficial da República Federativa do Brasil, Brasília, DF, v. 134, n.248, 23 dez.1996. Seção 1, p.27834-27841.

3. FÓRUM DE PRÓ-REITORES DE EXTENSÃO DAS UNIVERSIDADES PÚBLICAS BRASILEI- 
RAS - FORPROEX. Indissociabilidade ensino-pesquisa-extensão e a flexibilização curricular: uma visão da extensão. Coleção Extensão Universitária. Porto Alegre: UFRGS, Brasília: MEC/ SESu; v. 5, 2006. $100 \mathrm{p}$.

4. BRASIL. Constituição (1988). Constituição da República Federativa do Brasil. Belém: Basa, 1988.

5. FÓRUM DE PRÓ-REITORES DE EXTENSÃO DAS UNIVERSIDADES PÚBLICAS BRASILEIRAS - FORPROEX. Plano Nacional de Extensão Universitária. Coleção Extensão Universitária. Ilhéus: Editus, v. 1, 2001. 92p.

6. FÓRUM DE PRÓ-REITORES DE EXTENSÃO DAS UNIVERSIDADES PÚBLICAS BRASILEIRAS - FORPROEX. Extensão Universitária: organização e sistematização. Coleção Extensão Universitária. Org: Edison José Correa. Coordenação Nacional do FORPROEX, Belo Horizonte: Coopmed, v. 6, 2007. $112 \mathrm{p}$.

7. FÓRUM DE PRÓ-REITORES DE EXTENSÃO DAS UNIVERSIDADES PÚBLICAS BRASILEIRAS - FORPROEX. Avaliação Nacional da Extensão Universitária. Coleção Extensão Universitária. Brasília: MEC/SESu; UFPR; UESC, v. 3, 2001. 97p.

8. GUIMARÃES, R.G.M.; FERREIRA, M.C.; VILLAÇA, F.M. O Debate Necessário: a Importância da Extensão Universitária para a Formação Médica. Cadernos ABEM, vol.4, Out., Rio de Janeiro, 2008. p.69-78.

9. MALHEIROS, R; GUIMARÃES, R.G.M. Extensão Universitária e Formação Médica: uma análise da experiência dos bolsistas no programa "Escola Cidadã". Revista Brasileira de Educação Médica, Rio de Janeiro, v. 22, (2/3): 67-76, set. / dez. 1998.

10. GUIMARÃES, R.G.M. Que médico eu quero ser? Sobre a trajetória de jovens estudantes na construção da identidade médica. [Tese de Doutorado] Escola Nacional de Saúde Pública- ENSP, Rio de Janeiro, 2007.

11. TUTTMAN, M.T. Compromisso social da universidade: os olhares da extensão. [Tese de Doutorado] Universidade Federal Fluminense; 2005.

12. LUGARINHO,R. Consulta genética gratuita. Rio de Janeiro: PROEX / UNIRIO, 2004. 12p.

13. FERREIRA, M.L.C.R.; MALTA, M.T.B.P. Programa de Assistência Integral a Pessoa da Terceira Idade: Grupo Renascer. Rio de Janeiro: PROEX / UNIRIO, 1995. 20p.

14. COSTA, M.V.B.; PAMPLONA, T.C. Promoção de Leitura entre Jovens Leitores. Rio de Janeiro: PROEX / UNIRIO, 2004. 15p.

15. REIS, M.A.S. Etnoconhecimento para um Etnoreconhecimento. Rio de Janeiro: PROEX / UNIRIO, 2005. 43p.

16. MIDDLETON, S.R. Atenção Básica em Saúde nas Comunidades do Chapéu Mangueira e Babilônia. Rio de Janeiro: PROEX / UNIRIO, 2004. 22p.

17. SOARES, A.L.M; LIBERAL, E.F. Programa interdisciplinar de formação, ação e pesquisa: Enfermaria do Riso. Rio de Janeiro: PROEX / UNIRIO, 2004. 28p.

18. UNIVERSIDADE FEDERAL DO ESTADO DO RIO DE JANEIRO-UNIRIO. Plano de Gestão 20042008. Rio de Janeiro: UNIRIO, 2004.

19. UNIVERSIDADE FEDERAL DO ESTADO DO RIO DE JANEIRO-UNIRIO. Plano de Desenvolvimento Institucional - PDI, 2005-2010. Rio de Janeiro: UNIRIO, 2006.

20. UNIVERSIDADE FEDERAL DO ESTADO DO RIO DE JANEIRO - UNIRIO. Plano de Reestruturação da UNIRIO - REUNI / UNIRIO. Rio de Janeiro: UNIRIO, 2006.

21. PINHEIRO, D; CASTELO BRANCO, A.L.; SOUZA, M.E.V. Conexões de Saberes: diálogos entre a universidade e as comunidades populares -. SECAD/MEC e Observatório de Favelas. Rio de Janeiro: PROEX / UNIRIO, 2006. 33p. 
